\title{
On the aurora borealis of 26th Sept.
}

\section{Dr. T. Forster}

To cite this article: Dr. T. Forster (1828) On the aurora borealis of 26th Sept., Philosophical Magazine Series 2, 3:13, 75-76, DOI: 10.1080/14786442808674551

To link to this article: http://dx.doi.org/10.1080/14786442808674551

曲 Published online: 10 Jul 2009.

Submit your article to this journal

Џ Article views: 3

Q View related articles $₫$ 
me cast distinct shadows, though less strongly marked than when the moon is at the full.

8. Numerous sparks, of the apparent size of the smaller stars, but much more brilliant, were continually issuing from the ball of the meteor, and after descending a little distance, soon disappeared.

9. The length of time, in which the body was visible, was about eight, or possibly ten seconds.

10. A short time before its disappearance,-say one or two seconds, -three much larger sparks, or luminous fragments, were thrown from the body at the same moment. Two of these were apparently as large as the planet Venus; the third was still larger. These three were the last pieces which I saw leave the body. Their paths were at first nearly parallel with that of the meteor, yet beneath it. From this direction, however, they all deviated constantly and rapidly in parabolic curves, until they seemed falling perpendicularly towards the earth. Each fragment became less and less distinct, until it disappeared. The largest of the three continued visible until it was within about 20 degrees of the horizon.

11. The meteor itself disappeared as suddenly as if, in one indivisible moment, it had passed into a medium absolutely opaque, or as if, at a given moment, it had left the atmosphere; but a few moments afterwards there was a distinct and somewhat extensive illumination over that part of the sky for about a second, as if the light of the departing luminary had been reflected from some unknown surface to the earth.

12. When the meteor disappeared, it was about $30^{\circ}$ above the horizon, and, as I judged from the course of the fence, in the direction of N. $45^{\circ} \mathrm{E}$., or $25^{\circ}$ eastward of the place where I first saw it. I concluded that the direction of its path was probably from $W$. by $S$. to $\mathbf{E}$. by $N$. It was obviously going from me; its path making an angle with the optic axis of about $60^{\circ}$.

13. Not less than eight minutes, nor more than ten, after the disappearance of the meteor, there was a report very loud and heavy, accompanied with a very sensible jar. Though mistaken for thunder by those who did not see the meteor, it did not much resemble either thunder or the report of a cannon; but was louder, shorter and sharper than either, and was followed by no perceptible echo.

14. A friend of mine, who was in Berlin at the time, about 23 miles due N. of New Haven, saw the meteor distinctly, but made no particular observations concerning it. His estimate of it accorded generally with mine, but it appeared to him larger, more elevated, and somewhat more to the East in its apparent place. - I could not learn that the fragments which fell from it were discovered.-Silliman's Journal, vol. xiii. p. 35 .

ON THE AURORA BOREALIS OF 26TH SEPT.: BY DR. FORSTER.

Boreham, Nov. 95, 1827.

Having seen the remarkable aurora which occurred on the 26 th of September last, slightly mentioned in several of the journals, but no where accurately described, I send you the following brief notes on 
this remarkable phrnomenon, which I madeduring its continuance through the night of the $25 \mathrm{th}$, as it was seen by me and by others from the neighbourhood of Chelmsford in Essex.-I was passing the night at Boreham, and about nine o'clock P.M. I first noticed a very remarkable light in the North, the sky became intensely red in the N.N.E. and N., and afterwards very light all over the northern hemisphere. Clouds, however, soon obscured it for a time, and 1 returned to the house. At midnight on looking out of window, towards New Hall, I noticed the sky to be remarkably luminous, and on going out perceived every object as clearly as on a bright moonlight night. In the North the most brilliant streams of light shot up into the zenith from the horizon, generally in irregular diverging radii, whose centre appeared to be at nearly N.N.W. by N.; but other streamers of white light in other directions becoming alternately brilliant and faint appeared, while in E.N.E. and N.E. the whole sky seemed of a bright yellowish light : the red colour which I perceived at nine o'clock liad quite disappeared, and the white light continued to prevail till it was lost in the day-light of the following morning. It is recorded that on two former occasions, one about twenty years since, and the other early in the eighteenth century, bright auroras happened on the same day; namely, 25 th of September. I should like to have authenticated particulars of this fact, as it would establish a most remarkable coincidence of dates with the occurrence of this rare and beautiful phænomenon.

With regard to the aurora of the last 25th of September above described, I may observe, that I never saw distant objects so clearly on the brightest moonlight night as I did on that occasion at midnight ; but its light more resembled that of the break of day than of the moon, and hence the name of Aurora has not unaptly been applied to this meteor.

T. Forster.

LIST OF NEW PATENTS.

To R. Wheeler, of High Wycomb, for improvements on refrigerators for cooling fluids.-Dated the 22 nd of November $1827 .-6$ months allowed to enrol specification.

To W. J. Dowding, of Poulshot, Wiltshire, for improvements in machinery for rollering wool from the carding-engine.- 22 nd of November, -2 months.

To J. Roberts, of Wood-street, Cheapside, and G. Upton, of Queenstreet, Cheapside, for improvements on Argand and other lamps.24th of November. -6 months.

To J. A. Fulton, of Lawrence Pountney-lane, Cannon-street, London, for a process of preparing or bleaching pepper.-26th of November. -6 months.

To J. Apsey, of John-street, Waterloo-road, Lambeth, for an improvement in machinery to be used as a substitute for the crank.27 th of November.- 2 months.

To J. Jenour, jun., of Brighton-street, Pancras, for his cartridge or case, and method of more advantageously inclosing therein shot or other missiles for loading fire-arms, -28 th of November, -6 months. 